\title{
Falling and fall risk in adult patients with severe haemophilia
}

\author{
Hanna Rehm ${ }^{1 *}$; Jan Schmolders ${ }^{1 *}$; Sebastian Koob ${ }^{1 ;}$ Rahel Bornemann ${ }^{1 ;}$ \\ Georg Goldmann'; Johannes Oldenburg ${ }^{2}$; Peter Pennekamp ${ }^{2}$; Andreas C. Strauss ${ }^{1}$ \\ 'Department of Orthopaedics and Trauma Surgery, University of Bonn, Germany; \\ 2Institute for Haematology and Transfusion Medicine, University of Bonn, Germany
}

\section{Keywords \\ haemophilia, fall risk, adult}

\section{Summary}

The objective of this study was to define fall rates and to identify possible fall risk factors in adult patients with severe haemophilia. Patients, material, methods: 147 patients with severe haemophilia $A$ and $B$ were evaluated using a standardized test battery consisting of demographic, medical and clinical variables and fall evaluation. Results: 41 (27.9\%) patients reported a fall in the past 12 months, $22(53.7 \%)$ of them more than once. Young age, subjective gait insecurity and a higher number of artificial joints seem to be risk factors for falling. Conclusion: Falls seem to be a common phenomenon in patients with severe haemophilia. Fall risk screening and fall prevention should be implemented into daily practice.

Korrespondenzadresse

Andreas C. Strauss, MD

Department of Orthopaedics and Trauma Surgery

University of Bonn

Sigmund-Freud-Str. 25, 53127 Bonn, Germany

Tel. +49/(0)228287/14170, Fax +49/(0)288287/14175

E-mail: andreas.strauss@ukb.uni-bonn.de

* share senior authorship

\section{Schlüsselwörter}

Hämophilie, Sturzrisiko, Erwachsene

\section{Zusammenfassung}

Ziel der Untersuchung war es, die Häufigkeit von Sturzereignissen bei erwachsenen Hämophilie-Patienten zu untersuchen sowie mögliche Sturzrisikofaktoren zu identifizieren. Patienten, Material, Methoden: 147 Patienten mit schwerer Hämophilie A und B wurden mittels einer standardisierten Testbatterie, bestehend aus demografischen, medizinischen und klinischen Variablen sowie der Sturzanamnese, untersucht. Ergebnisse: 41 (27.9\%) Patienten stürzten in den letzten 12 Monaten, $22(53.7 \%)$ davon mehr als ein Mal. Junges Alter, subjektive Gangunsicherheit und eine höhere Anzahl an endoprothetisch versorgten Gelenken scheinen Risikofaktoren für einen Sturz zu sein. Schlussfolgerung: Stürze waren ein häufiges Phänomen unter den Studienteilnehmern. Es erscheint sinnvoll, Screeningmaßnahmen sowie prophylaktische Maßnahmen zu etablieren, um Patienten mit besonders hohem Sturzrisiko zu identifizieren und Sturzereignisse zu vermeiden.

Sturzereignisse und Sturzrisiko bei Erwachsenen mit schwerer Hämophilie

Hämostaseologie 2017; 37: 97-103 http://dx.doi.org/10.5482/HAM0-16-03-0009 received: March 30, 2016

accepted in revised form: September 7, 2016

epub ahead of print: September 23, 2016

Funding

The authors thank Baxalta for the research grant to the study
Advances in haemophilia care have resulted in increases in median life expectancy for patients with haemophilia (PWH) (1). Falls are a well-explored phenomenon in elderly nonhaemophilic people. Ageing is known to be associated with a higher risk of falling. $28-35 \%$ of the community-dwelling population aged $\geq 65$ years fall at least once a year (2).

In addition to extrinsic risk factors (e.g. environmental hazards like slippery floors, poor lighting or inappropriate footwear), many intrinsic risk factors can increase the risk of falling, e.g.

- history of falls,

- impaired gait and mobility,

- visual impairments or

- fear of falling (3-5).

Many of the identified fall risk factors can be found in PWH. For PWH fall risk could be additionally increased by haemophilic arthropathy particularly affecting the lower $\operatorname{limb}(1,6)$.

Data on falling and fall risk factors in PWH is very limited. To the best of our knowledge only 2 studies have been published so far that examined the occurrence of falls in PWH:

- Fearn et al. reported a fall incidence of $50 \%$ in 20 patients with mild, moderate and severe haemophilia in the preceding 12 months (7).

- Sammels et al. reported a fall incidence of $32 \%$ in 74 patients with moderate and severe haemophilia during the preceding 12 months (8).

The objective of the present study was to define fall rates and to identify possible fall risk factors in PWH. Additionally the relationship between scores on fall risk assessment tools and actual fall rates was evaluated.

\section{Patients, material, methods Design and sample}

A descriptive, retrospective study was conducted. The data collection was performed between December 2014 and August 2015. The patients were recruited during their regular visit at the haemophilia care centre in Bonn. Written informed consent was obtained from all participants. 
Community-dwelling adults aged 18 years or older with severe haemophilia A and $B$ were included into the study.

Patients that were not independent in their mobility (e.g. patients that were fully bedridden or wheelchair-bound) and patients that suffered from other comorbidities that could influence the risk of falling (e.g. parkinsons' disease, epilepsy) were excluded.

The study protocol was approved by the Medical Ethics Committee of the Rheinische Friedrich-Wilhelms-Universität Bonn.

\section{Variables and measurement}

Data was collected using a standardized test battery. General information like age and body mass index (BMI) were recorded. Medical variables were obtained from the patients' records, such as
- type and severity of haemophilia,

- number of bleedings in the last 12 months,

- treatment modalities and

- factor concentrate consumption in the last 12 months.

Duration and reason of hospitalisation in the last 12 months and number of joint prostheses were also recorded. The Haemophilia joint health score (HJHS) (9) is regularly assessed by the staff of the haemophilia care centre; results were obtained from the patients' records as well.

A fall was defined as an "unexpected event in which the patient comes to rest on the ground, floor or lower level" (10). A fall questionnaire was designed, asking the patients about fall rates in the last 12 months. Concerning the last fall, data on cause, location and consequences (additional factor consumption, injuries, medical consultation, pain) were collected.

To gain insight into the patients' subjective gait perception we included the statement "I often feel insecure when walking". The patients were asked on how much they agreed with that sentence on a 5-step Likert scale from 1: „I strongly disagree” to 5: „I strongly agree”.

To explore possible fall risk factors the patients were asked to fill out questionnaires concerning

- fear of falling (Falls efficacy scale - international version; FES-I) (11),

- functional health status (Haemophilia activities list; HAL) (12) and

- quality of life (Short form 36; SF36) (13).

Furthermore, joint pain was recorded using the visual analogue scale (VAS).

Tab. 1 Comparison between non-fallers and fallers and between one-time fallers and multiple fallers (values given as mean \pm standard deviation for normally distributed variables, respectively median (interquartile ranges) for non-normally distributed variables). Significant differences were evaluated with the Mann-WhitneyU-test for non-normally distributed data, normally distributed data were evaluated using the Student's t-test. * ${ }^{*}$ statistically significant $(p<0,05)$.

\begin{tabular}{|c|c|c|c|c|c|c|c|}
\hline \multirow[b]{2}{*}{ Parameter } & \multirow[b]{2}{*}{ total $(n=147)$} & \multicolumn{3}{|c|}{ non-fallers vs. fallers } & \multicolumn{3}{|c|}{ one-time vs. multiple fallers } \\
\hline & & $\begin{array}{l}\text { non-fallers } \\
(n=107)\end{array}$ & fallers $(n=41)$ & $p$-value & $\begin{array}{l}\text { one-time fallers } \\
(n=19)\end{array}$ & $\begin{array}{l}\text { multiple fallers } \\
(n=22)\end{array}$ & $p$-value \\
\hline age & $42.39 \pm 14.51$ & $41.9 \pm 13.76$ & $43.46 \pm 16.45$ & 0.072 & $48.79 \pm 13.92$ & $38.86 \pm 17.36$ & 0.058 \\
\hline BMI $\left(\mathrm{kg} / \mathrm{m}^{2}\right)$ & $25.02 \pm 4.6$ & $25.28 \pm 13.76$ & $24.33 \pm 3.92$ & 0.288 & $24.20 \pm 2.78$ & $24.44 \pm 4.75$ & 0.096 \\
\hline $\begin{array}{l}\text { factor consumption } \\
\text { past year (IU) }\end{array}$ & $447893 \pm 463288$ & $438551 \pm 470508$ & $472567 \pm 448694$ & 0.358 & $3661972 \pm 248729$ & $567362 \pm 556319$ & 0.151 \\
\hline $\begin{array}{l}\text { number of bleedings } \\
\text { past year }\end{array}$ & $1.77 \pm 3.47$ & $1.8 \pm 3.85$ & $1.7 \pm 2.22$ & 0.107 & $1.63 \pm 2.14$ & $1.76 \pm 2.34$ & 0.921 \\
\hline $\begin{array}{l}\text { hospitalisation days } \\
\text { past year }\end{array}$ & $2.18 \pm 5.78$ & $1.89 \pm 5.75$ & $2.95 \pm 5.86$ & $0.049^{*}$ & $3.16 \pm 7.31$ & $2.77 \pm 4.43$ & 0.435 \\
\hline $\begin{array}{l}\text { number of joint } \\
\text { protheses }\end{array}$ & $0.35 \pm 0.77$ & $0.27 \pm 0.70$ & $0.56 \pm 0.91$ & $0.024^{*}$ & $0.72 \pm 1.13$ & $0.43 \pm 0.68$ & 0.649 \\
\hline $\begin{array}{l}\text { subjective gait } \\
\text { insecurity }\end{array}$ & $1.92 \pm 1.1$ & $1.79 \pm 1.06$ & $2.24 \pm 1.24$ & $0.029^{*}$ & $2.11 \pm 0.99$ & $2.36 \pm 1.43$ & 0.765 \\
\hline TUG (s) & $11.46 \pm 7.51$ & $11.54 \pm 1.06$ & $11.28 \pm 4.62$ & 0.215 & $11.68 \pm 4.81$ & $10.94 \pm 4.53$ & 0.353 \\
\hline HAL & $76.79 \pm 23.28$ & $77.87 \pm 23.09$ & $74.01 \pm 23.82$ & 0.371 & $73.10 \pm 21.59$ & $74.80 \pm 26.07$ & 0.521 \\
\hline FES-I & $21.63 \pm 8.08$ & $20.9 \pm 7.31$ & $23.54 \pm 9.47$ & 0.089 & $23.05 \pm 8.44$ & $23.95 \pm 10.46$ & 0.635 \\
\hline SF36: PCS & $43.72 \pm 11.90$ & $43.84 \pm 12.13$ & $43.39 \pm 11.45$ & 0.757 & $43.97 \pm 9.70$ & $42.88 \pm 12.99$ & 1.000 \\
\hline SF36: MCS & $52.51 \pm 11.23$ & $53.29 \pm 10.32$ & $50.53 \pm 13.21$ & 0.423 & $52.79 \pm 13.61$ & $48.57 \pm 12.84$ & 0.210 \\
\hline $\begin{array}{l}\text { number of painful } \\
\text { joints }\end{array}$ & $3.59 \pm 3.01$ & $3.59 \pm 3.04$ & $3.56 \pm 2.98$ & 0.998 & $3.32 \pm 2.36$ & $3.77 \pm 3.48$ & 0.979 \\
\hline HJHS & $23.57 \pm 23.41$ & $22.16 \pm 22.47$ & $27.18 \pm 25.62$ & 0.448 & $30.79 \pm 26.47$ & $23.90 \pm 25.02$ & 0.316 \\
\hline
\end{tabular}

TUG: timed up and go test, HAL: haemophilia activities list, FES-I: falls efficacy scale, SF36: short form 36,

PCS: physical component summary, MCS: mental component summary, $\mathrm{HJH}$ : haemophilia joint health score 
Data collection was completed by a physical examination consisting of the Timed up and Go Test (TUGT) (14).

\section{Statistics}

Descriptive statistics of mean, standard deviation, percentages and frequencies were calculated for all variables.

Differences between the means of two groups (e.g. fallers vs. non-fallers) were assessed with independent $t$-test for normally distributed interval or ratio values.

Non-normally distributed interval or ratio values or ordinal variables were analysed using the Mann-Whitney-U-test.

Bivariate logistic regression was conducted to examine variables associated with falls. A value of $p<0.05$ was considered statistically significant.

The data was analysed by using SPSS Version 22.0 (IBM Corp., Armonk, NY, USA) and Stata Statistical Software 14 (StataCorp LP, College Station, TX, USA).

\section{Results}

\section{Description of the sample}

147 male patients with severe haemophilia (factor level of $<1 \%$ ) participated in the study. The average age was $42.4 \pm 14.5$ years (range 18-74). 132 patients $(89,8 \%)$ had haemophilia A, 15 (10.2\%) haemophilia B.

4 patients $(2.7 \%)$ had inhibitors at the time of the examination. Almost all patients $(142,96.6 \%)$ were under prophylactic treatment; the other 5 patients (3.47\%) applied clotting factor concentrates on demand. The average factor concentrate consumption in the last 12 months was $447893 \pm 463288$ IU. The average number of bleedings in the last 12 months was $1.77 \pm 3.47$ (range $0-26$ ).

\section{Fall rates, circumstances and consequences}

41 patients $(27,9 \%)$ reported at least one fall within the last 12 months, 22 (53.7\%) of them more than one. Most of the falls occurred outside the patients' home (70.7\%); $69 \%$ of them outdoors, $31 \%$ indoors. When asked for the cause of a fall, most patients answered "tripping" (44\%) or "slipping" ( $28 \%)$; sports or physical activity were also frequently named (15\%).

More than half of the patients who fell (53.7\%) suffered from fall-related injuries afterwards:

- 9 patients (40.9\%) had mild injuries like superficial wounds or bruises,

- 11 (50\%) reported a bleeding after the fall and

- $2(9.1 \%)$ reported a fracture.

\section{Comparison of non-fallers vs.}

fallers and one-time vs. multiple fallers

After dividing the patients into groups (non-fallers, fallers, one-time fallers and multiple fallers), differences between the medical and clinical variables of these groups were evaluated using the MannWhitney-U-test. Tab. 1 shows part of that comparison. Between fallers and nonfallers 3 significant differences were noted:

1. Fallers spent significantly more days in a hospital during the last year than nonfallers $(2.95 \pm 5.86$ vs. $1.89 \pm 5.75$, $\mathrm{p}=0.049)$. The days spent in inpatient care were all non-fall related and mostly due to elective orthopaedic procedures like joint replacement or radiosynoviorthesis.

2. Fallers had on average a higher number of joint prostheses than non-fallers $(0.56 \pm 0.91$ vs. $0.27 \pm 0.70, p=0.024)$.

3. When asked for their subjective perception, fallers indicated a higher level of gait insecurity than non-fallers ( $2.24 \pm 1.24$ vs. $1.79 \pm 1.06$ on a 5 -point Likert scale, $\mathrm{p}=0.029$ ).

In comparison of one-time fallers and multiple fallers, age was only the parameter that differed significantly: Multiple fallers were significantly younger than one-time fallers $(38.86 \pm 17.36$ years vs. $48.79 \pm 13.92$ years, $\mathrm{p}=0.043)$. Neither concerning the fall risk assessment tools (e.g. FES-I, TUGT), nor the joint status (HJHS) or pain levels (VAS) significant differences were found between the groups.

Taking these results into account a binary logistic regression was conducted. The following predictors were included into the regression model:

- age,

- subjective gait insecurity,

- duration of hospitalisation in the past year and

- number of joint prostheses.

Tab. 2 Factors influencing fall risk in adult haemophilia patients. Logistic regression $(n=136)$, Pseudo $\mathrm{R} 2=0,1475$, "statistically significant $(p<0,05)$. Odds Ratios for "age" and "subjective gait insecurity" to be interpreted in relation to the reference category. Odds Ratios for "hospitalisation past year" and "number of joint prostheses" indicate the odds ratio for a one-unit change in the respective variable.

\begin{tabular}{|l|l|l|l|l}
\hline \multicolumn{2}{|l|}{} & Odds ratio & $\begin{array}{l}95 \% \text { confidence } \\
\text { interval }\end{array}$ & p-value \\
\hline age $^{1}$ & $31-40$ years & 0.12 & $0.02-0.66$ & $0.019^{*}$ \\
& $41-50$ years & 0.25 & $0.07-0.90$ & \\
\hline $51-60$ years & 0.05 & $0.01-0.43$ & \\
\cline { 2 - 5 } & $>60$ years & 0.03 & $0.00-0.34$ & \\
\hline $\begin{array}{l}\text { subjective gait } \\
\text { insecurity }\end{array}$ & 2 & 1.18 & $0.48-6.79$ & $0.027^{*}$ \\
& 3 & 5.69 & $1.35-23.96$ & \\
\hline $\begin{array}{l}\text { hospitalisation past } \\
\text { year (days) }\end{array}$ & - & 10.68 & $1.93-58.97$ & \\
\hline $\begin{array}{l}\text { number of joint } \\
\text { prostheses }\end{array}$ & - & 31.04 & $1.88-512.33$ & 0.629 \\
\hline
\end{tabular}

${ }^{1}$ reference category: $18-30$ years

${ }^{2}$ reference category: 1 (strongly disagree) 


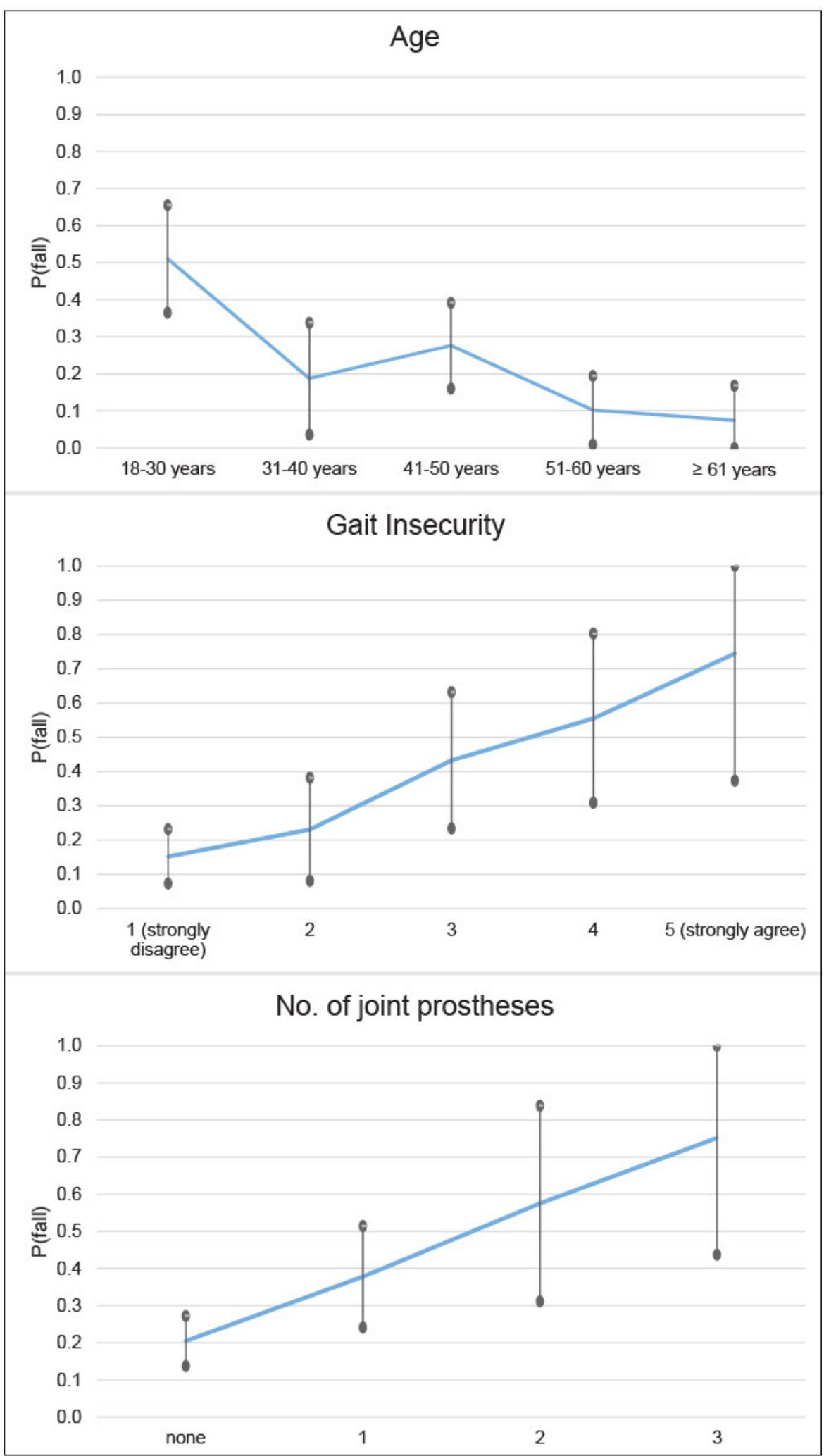

Fig. 1 Probability of falling $[P(f a l l)]$ in \% for the three identified risk factors "age", "gait insecurity" and "number of joint prostheses" based on the logistic regression model. Marked are the $95 \%$ confidence intervalls.
The outcome was defined as whether a patient did or did not fall in the past year. After excluding patients with missing values and identifying influential values (Cooks D $>4$ / 147), 136 patients were included into the model. 3 of the 4 parameters showed significant influence on the outcome fall/no fall in the past year ( Tab. 2). The probability of a fall is shown in $>$ Fig. 1 , separately for the 3 significant variables age, gait insecurity and joint replacement.

Fall probability increased almost linear with gait insecurity and joint replacement: The more insecure the patients felt while walking or the more joints he had replaced, the higher was the probability to fall.

Concerning age as an independent predictor of a fall a decreasing fall risk with higher age was found. Based on the mathematical regression model patients between 18 and 30 years had the highest probability to fall $(50 \%)$. The probability of a fall decreased until it reached its minimum for patients older than 60 years (probability of fall: less than $10 \%)$.

\section{Discussion}

Falls are usually multifactorial in their origin; especially in the elderly population many factors can contribute to an overall increased risk of falling. In addition to fall risk factors present in the general population, PWH show disease-specific characteristics that could lead to an increased risk of falling at a younger age (e.g. balance deficits, haemophilic arthropathy) (15).

So far there is a lack of literature on falls in PWH. Our study is the first study to examine exclusively adult patients with severe haemophilia aged 18 years and older. Patients with mild and moderate haemophilia rarely present with haemophilic arthropathy and associated musculoskeletal co-morbidities that could contribute to a higher risk of falling.

The fall incidence we found was considerably lower than the one Fearn et al. reported in 2010 (27.9vs. $50 \%$ in the last 12 months) (7). Fearn et al. included 20 patients with mild, moderate and severe haemophilia (average age 39.4 years, range: 22-58) and compared them to a non-haemophilic control group. The higher fall in- 
cidence might be due to the very small sample size.

Sammels et al. reported a fall incidence of $32 \%$ in 74 patients with moderate and severe haemophilia, which is comparable to the incidence we found (8).

So far there has only been one study that systematically evaluated different fall risk factors in PWH (8). Up to this point our study is the largest study examining falling and fall risk factors in PWH: Age, number of joint prostheses and subjective gait insecurity have a significant influence on falls in PWH. In the general population high age is often associated with a higher risk of falling (2).

Unexpectedly, in our study younger PWH showed a higher probability to fall compared to elderly patients. This can most likely be explained with higher activity levels combined with a higher willingness to take risks in young PWH.

Due to the treatment opportunities available nowadays even patients with severe haemophilia can lead almost normal lives.

In our study the probability to fall increased almost linearily with the number of joint prostheses. This is in accordance with the study of Sammels et al., who found a higher incidence of joint replacement in multiple fallers compared to non-fallers (8). In the general population the literature is inconsistent regarding joint replacement as a fall risk factor:

- Swinkels et al. suppose a reduction in fall prevalence for patients after knee replacement surgery (16).

- Levinger et al. on the other side found an increased fall risk in patients after knee replacement surgery (17).

In PWH both knee and hip replacement have been shown to improve function and reduce pain (18-20). However, according to our results, the probability to fall increases with the number of joint prostheses. On the one hand joint arthroplasty results in an improvement of function and reduction of pain, but on the other hand proprioceptive deficits and reduced muscle strength are reported regularly $(21,22)$. Both proprioceptive deficits and reduced muscle strength can lead to gait impairments and thereby gait insecurity. Impaired lower extremity proprioception - especially in patients with multiple joint prostheses could lead to the strong increase in fall risk.

Interestingly none of the fall risk assessment tools showed significant differences between fallers and non-fallers. No significant difference between fallers and non-fallers in the results of the TUG was found. It is often suggested, that the TUG is a good measure for basic mobility and therefore also a good indicator of fall risk $(23,24)$. Even though not statistically significant, we found that both fallers and multiple-fallers were on average faster in completing the TUG than non-fallers.

The TUG seems to be a good fall risk assessment tool for elderly patients; when assessing young patients its results seem to be less conclusive.

In contrast to the comparatively complicated and time-consuming assessments like the TUG or the FES-I the simple question "Do you feel insecure when walking" seems to be a good indicator of fall risk: The more insecure patients felt when walking (i.e. the more strongly they agreed to the statement) the higher was the probability to fall. Multiple factors can influence a patients' subjective perception of gait (in)security, e.g. gait, fear of falling and history of falling. To ask the patient directly about his/her perception of gait (in)security might be a fast and easy way to identify patients with a higher risk of falling.

\section{Limitations}

The main limitation of our study is the retrospective study design. Studies have shown that retrospective studies underestimate the fall incidence by up to $13-32 \%$. Recalling a fall in the past 12 months can be difficult for patients, especially if the fall did not have serious consequences ("recall bias") (25). The close contact between patients and health care professionals in haemophilia care centres helped us to minimize these recall bias by double checking the information with the patients' records.

Another limitation is the lack of a nonhaemophilic control group. To identify fall risk factors specific for $\mathrm{PWH}$ a prospective multicentric study with a large sample of adult PWH and a non-haemophilic control group should be conducted.

\section{Conclusion}

Falls seem to be a common phenomenon in patients with haemophilia. Screening for fall risk factors like age, joint replacement and gait insecurity should be implemented into the daily practice of haemophilia care to prevent falling. Both patients and healthcare professionals need to be aware of the alling risk and the possible consequences a fall might have - especially for elderly patients.

Fall prevention strategies such as physiotherapy should be stimulated.

\section{Authorship contribution}

Hanna Rehm, Jan Schmolders and Peter Pennekamp performed chart review, data collection and wrote the paper. Rahel Bornemann, Georg Goldmann and Sebastian Koob performed chart review and collection of clinical data; Andreas Strauss and Johannes Oldenburg analysed results and edited the manuscript.

\section{Conflict of interest}

Peter H. Pennekamp and Andreas C. Strauss have received funding for research carried out in this work. The other authors declare that they have no interests which might be perceived as posing a conflict or bias.

\section{Literature}

1. Mauser-Bunschoten EP, Fransen Van De Putte DE, Schutgens REG. Co-morbidity in the ageing haemophilia patient: the down side of increased life expectancy. Haemophilia 2009; 15: 853-863.

2. Masud T, Morris RO. Epidemiology of falls. Age Ageing 2001; 30(Suppl 4): 3-7.

3. Tinetti ME, Speechley M, Ginter SF. Risk factors for falls among elderly persons living in the community. N Engl J Med 1988; 319: 1701-1707.

4. Rubenstein LZ. Falls in older people: epidemiology, risk factors and strategies for prevention. Age Ageing 2006; 35(Suppl 2): ii37-ii41.

5. WHO Europe. What are the main risk factors for falls among older people and what are the most effective interventions to prevent these falls (March 2004)? http://www.euro.who.int/_data/assets/ 
pdf_file/0018/74700/E82552.pdf (access on 9th September 2016)

6. Forsyth AL, Quon DV, Konkle BA. Role of exercise and physical activity on haemophilic arthropathy, fall prevention and osteoporosis. Haemophilia 2011; 17: 870-876.

7. Fearn M, Hill K, Williams S et al. Balance dysfunction in adults with haemophilia. Haemophilia 2010; 16: 606-614.

8. Sammels M, Vandesande J, Vlaeyen E, Peerlinck K, Milisen K. Falling and fall risk factors in adults with haemophilia: an exploratory study. Haemophilia 2014 ; 20: 836-845.

9. Hilliard P, Funk S, Zourikian N, Bergstrom BM et al. Hemophilia joint health score reliability study. Haemophilia 2006; 12: 518-525.

10. Lamb SE, Jørstad Stein EC, Hauer KA, Becker C. Development of a common outcome data set for fall injury prevention trials: the Prevention of Falls Network Europe Consensus. J Am Geriatr Soc 2005; 53: 1618-1622.

11. Dias N, Kempen GIJM, Todd CJ et al. The German version of the Falls Efficacy Scale-International Version (FESI). Z Gerontol Geriatr 2006; 39: 297-300.

12. van Genderen FR, Westers P, Heijnen L et al Measuring patients' perceptions on their func- tional abilities: validation of the Haemophilia Activities List. Haemophilia 2006; 12: 36-46.

13. Ware JE, Sherbourne CD. The MOS 36-item shortform health survey (SF-36). I. Conceptual framework and item selection. Med Care 1992; 30: 473-483.

14. Podsiadlo D, Richardson S. The timed "Up \& Go": a test of basic functional mobility for frail elderly persons. J Am Geriatr Soc 1991; 39: 142-148.

15. Flaherty LM, Josephson NC. Screening for fall risk in patients with haemophilia. Haemophilia 2013 19: 103-109.

16. Swinkels A, Newman JH, Allain TJ. A prospective observational study of falling before and after knee replacement surgery. Age and Ageing 2009; 38 175-181.

17. Levinger P, Menz HB, Wee E et al. Physiological risk factors for falls in people with knee osteoarthritis before and early after knee replacement surgery. Knee Surg Sports Traumatol Arthrosc 2011; 19: 1082-1089.

18. Silva M, Luck JV. Long-term results of primary total knee replacement in patients with hemophilia. J Bone Joint Surg Am 2005; 87: 85-91.

19. Habermann B, Eberhardt C, Hovy L et al. Total hip replacement in patients with severe bleeding disorders. Int Orthop 2007; 31: 17-21.
20. Strauss AC, Schmolders J, Friedrich MJ et al. Outcome after total knee arthroplasty in haemophilic patients with stiff knees. Haemophilia 2015; 21: 300-305.

21. Pap G, Meyer M, Weiler HT et al. Proprioception after total knee arthroplasty: a comparison with clinical outcome. Acta Orthop Scand 2000; 71: 153-159.

22. Fuchs S, Thorwesten L, Niewerth S. Proprioceptive function in knees with and without total knee arthroplasty. Am J Phys Med Rehabil 1999; 78: $39-45$.

23. de Kleijn P, van Genderen FR, van Meeteren NLU. Assessing functional health status in adults with haemophilia: towards a preliminary core set of clinimetric instruments based on a literature search in Rheumatoid Arthritis and Osteoarthritis. Haemophilia 2005; 11: 308-318.

24. Rao SS. Prevention of falls in older patients. Am Fam Physician 2005; 72: 81-88.

25. Cummings SR, Nevitt MC, Kidd S. Forgetting falls. The limited accuracy of recall of falls in the elderly. J Am Geriatr Soc 1988; 36: 613-616. 